\title{
Effect of anesthesia on acoustically evoked middle latency response in guinea pigs
}

\author{
J.A. Crowther ${ }^{1}$, J.M. Miller ${ }^{2}$ and P.R. Kileny ${ }^{2}$ \\ 'Department of Otolaryngology, Glasgow Royal Infirmary, Glasgow; U.K. and ' Kresge Hearing Rearech Institute. \\ Department of Otolaryngology. The University of Micnigan, Ann Arbor, Michigan, U.S.A.
}

(Received 27 April 1989; accepted 5 August 1989)

\begin{abstract}
Increased recent interest in the middle latency response (MLR) has necessitated a clarification of the possible effects of anesthesia on the response. Our study was designed to examine the changes, in the guinea pig MLR, which occurred during anesthesia with ketamine, xylazine or both ketamine and xylazine. Under anesthesia the response remained present and the threshold remained stable. After anesthesia, significant changes in amplitude. latency, and general morphology of the waveform took place, however these were consistent and predictable. For studies requiring the MLR, it is best to avoid anesthetic agents. However, with care the MLR can be used as a reliable measure of auditory system sensitivity under anesthesia.
\end{abstract}

Middle latency response; Ketamine: X:lazine; Guinea pig; Auditory system sensitivity; Anesthesia

\section{Introduction}

In recent years there has been renewed interest in the middle latency auditory response (MLR). MLRs follow the ABR in the time domain over a 10 to $100 \mathrm{~ms}$ range. In humans, such responses are most prominent when recorded over fronto-central scalp as a triphasic wave, with an initial positive peak $(\mathrm{Pa})$ at $25-30 \mathrm{~ms}$ being the most stable component. Clinical applications include hearing threshold measurement (Kileny and Shea, 1986), neurological applications (Ho et al., 1987), and intra-operative monitoring (Kileny et al., 1983). More recentiy, it has been suggested that electrically evoked middle latency response (EMLR) may be 2 useful indicator of eighth nerve survival in cochlear implant candidates (Gardi, 1985; Kileny and Kemink, 1987; Jyung et al., 1989). Further research on human and animal MLRs are needed to clarify their potential value in clinical practice.

Correspondence to: Josef M. Miller, Kresge Hearing Research 1.:stitute, The University of Michigan, 1301 East Ann Street, Ann Arbor, MI 48109-0506, U.S.A.
The MLR has been well characterized in the guinea pig (McGee et al., 1983; Kraus et al., 1985; Ozdamar et al., 1986; Kraus et al., 1987) and is best recorded over the temporal lobe contralateral to the stimulated ear. It is a triphasic waveform consisting of two positive waves separated by a negative trough, the waves being labeled $A, B$, and C. Burton et al. (1988a, b) and Jyung et al. (1989) demonstrated that an EMLR could be elicited in the guinea pig by round window stimulation and showed the similarity between electrical and acoustically evoked responses.

The effect of anesthesia on the MLR remains controversial. Kileny et al. (1983) has examined changes in the human MLR caused by anesthetic agents and McGee et al. (1983) and Smith and Kraus (1987) described changes seen in the MLR of guinea pigs under anesthesia. Since many animal experiments evaluating the MLR are performed with anesthesia, it is important that possible changes in MLR amplitude latency and particularly threshold caused by anesthesia, are recognized in order to correctly interpret results.

Ketamine, a dissociative anesthetic, and xylazine (rompun $\mathbb{B}$ ), a non-narcotic muscle relaxant 
and hypnotic with analgesic properties (Detweiler et al., 1968), are trequentiy used individually or in combination with one another to provide surgical anesthesia in many animal studies and routinely in guinea pigs (Green et al., 1981; Hart et al., 1984; Brown et al., 1989). Previously, we reported a significant depression in the electrically evoked MLR as a result of a combination of xylazine and ketamine (Crowther et al., 1989). These changes were predictable in time and restricted to suprathreshold features of the EMLR. Threshold features were unaffected by anesthesia. The aim of this study was to define the effect of these two commonly used anesthetic agents, when used individually or combined, on threshold, suprathreshold and waveform features of the acoustically evoked MLR.

\section{Methods}

Five albino guinea pigs weighing $300-500 \mathrm{~g}$ were used. They were anesthetized with intramuscular ketamine and xylazine. Under aseptic conditions, two stainless steel screws were inserted through holes drilled in the cranium for epidural recording electrodes. One was located $2 \mathrm{~cm}$ anterior to the bregma (reference electrode), and the other $1 \mathrm{~cm}$ lateral to the bregma on the side opposite to the ear to be stimulated (active electrode). A larger screw was attached to the skull to be used with the restraining device. Screws were secured with dental acrylic.

At least $72 \mathrm{~h}$ following surgery, each animal was placed in a restraining device for a first recording session. An enclosed PDR 600 (Permaflux) ear speaker was coupled to the ear to be stimulated by a short tube placed in the external canal. Responses were recorded between implanted electrode screws and a needle electrode inserted into the neck muscle as ground. These were amplified 100 times by a Grass P15 preamplifier with filters set at $3 \mathrm{~Hz}$ to $3000 \mathrm{~Hz}$, and a filter roll-off of $6 \mathrm{~dB}$ per octave. The signal was further amplified 100 times by a home produced amplifier with bandpass of $0.5 \mathrm{~Hz}$ to $30,000 \mathrm{~Hz}$. The responses obtained from 200 stimulus presentations were averaged using a $\mathrm{MI}^{2}$ signal processor system (Modular Instruments Inc, Southeastern,
PA). A heating pad was used to maintain body temperature at $38^{\circ} \mathrm{C}$.

The acoustic stimulus was a click generated by $0.2 \mathrm{~ms}$ square voltage pulse led to the ear speaker (maximum ouiput equalled $119 \mathrm{~dB}$ peak equivalent SPL) at a rate of $5 / \mathrm{s}$. The order of presentation of stimuli at different intensities was varied to counter-balanced sequential effects. Intensities, in $10 \mathrm{~dB}$ steps, from that yielding a threshold response to that yielding a maximum MLR were examined. Threshold was defined as the lowest intensity at which the typical MLR pattern could be replicated. For threshold determination intensity was varied about the estimated threshold in 5 dB steps. From these responses, amplitude-intensity and latency-intensity input/output (1/O) functions were derived. Amplitude functions were based on measurement of the A-B peak-to-peak amplitude and B-C peak-to-peak amplitude. Latency functions were derived from measurement of each peak: A, B, and C.

Response functions were first recorded in the unanesthetized animal, followed by observations made under anesthesia. An intramuscular injection of anesthetic, either 1) ketamine $(100 \mathrm{mg} / \mathrm{kg})$, 2) xylazine $(13.3 \mathrm{mg} / \mathrm{kg})$ or 3$)$ ketamine $(130$ $\mathrm{mg} / \mathrm{kg}$ ) combined with xylazine $(13.3 \mathrm{mg} / \mathrm{kg})$ was given and responses were then recorded at 15 and $30 \mathrm{~min}$ and every $30 \mathrm{~min}$ thereafter to $3 \mathrm{~h}$. Recordings were also taken at $24 \mathrm{~h}$. Each animal received all three anesthetic combinations, each separated by at least $48 \mathrm{~h}$.

\section{Results}

Fig. 1 illustrates a typical MLR waveform, with labeled peaks, as recorded in the unanesthetized guinea pig. There are changes in both amplitude and latency of the MLR which are common to all three anesthetic combinations, although the threshold is little affected $(<10 \mathrm{~dB})$. The magniiude and duration of these changes are dependent on the anesthetic agent.

\section{Amplitude}

The peak-to-peak amplitude of waveforms A-B and B-C are initially depressed followed by a gradual rise to above unanesthetized baseline levels. Figs. 2 and 3 show the mean change in the 


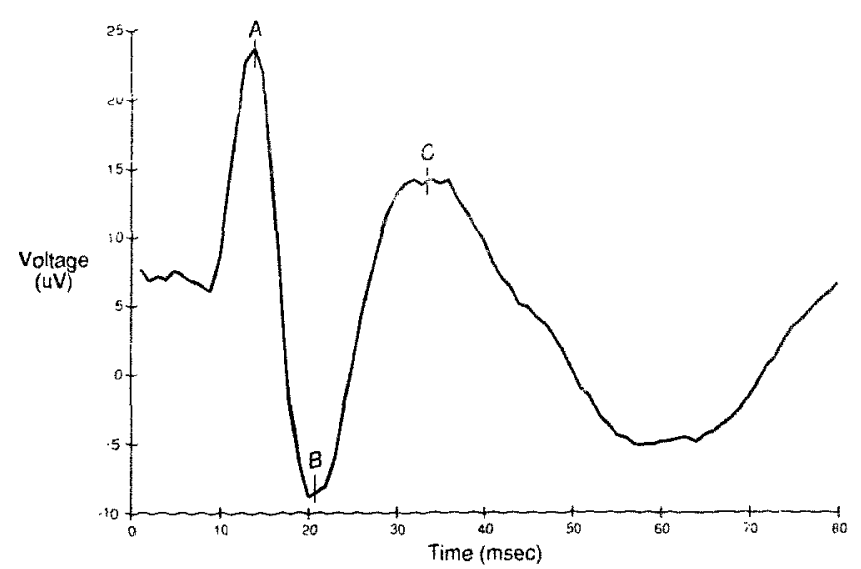

Fig. 1. Representative MLR response recorded in an unanesthetized chronically implanted guinea pig. Typical A, B, and $\mathrm{C}$ waves are appropriately labeled.

amplitudes of A-B and B-C waves over time with a constant intensity stimulus (see figure legends) following anesthesia. This effect is common to all three anesthetic regimes but the depressant effect of ketamine is of shorter duration and recovery of baseline and amplitude overshoot is reached earlier than with xylazine. Combining ketamine with xylazine causes a greater and more prolonged depressant effect and the amplitude overshoot although delayed, is greater. The observed amplitude overshoot coincided with recovery from anesthesia and return of withdrawal reflex. This occurred earliest with ketamine and latest with ketamine with xylazine. With anesthesia supple-

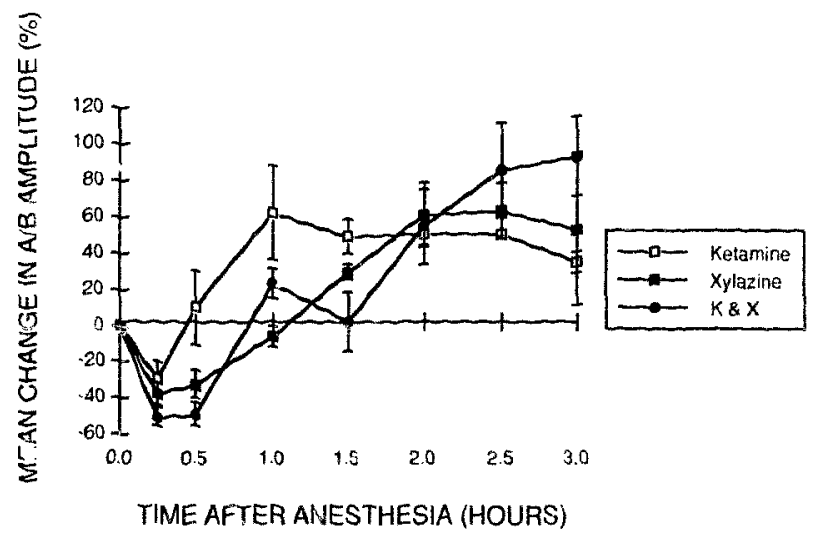

Fig. 2. Mean amplitude of the A-B peak-to-peak response over time following administration of anesthesia. Mean values based on observations in five subjects. Vertical bars represent $+/-1$ S.D.

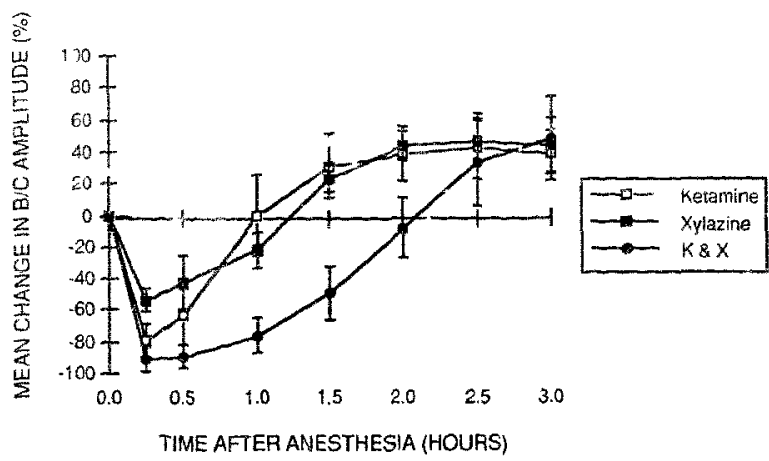

Fig. 3. Mean amplitude of the B-C peak-to-peak response over time following administration of anesthesia. Mean values based on observations in five subjects. Vertical bars represent $+/-1$ S.D.

ment at this stage, the amplitude is again sepressed in a dose dependent fashion.

The effect of these anesthetic induced changes in the A-B amplitude $1 / O$ function is shown in Fig. 4 for a representative subject with ketamine with xylazine. At a period of $15 \mathrm{~min}$ foil ring anesthesia, depression in the $1 / 0$ function is greatest (labeled 'minimum'), similar to the tirne course of effect seen in Fig. 3. At $2 \mathrm{~h}$ postanesthesia there is a marked increase in the slope of the $1 / O$ function and a clear sloping saturation of the response function is seen (labeled 'maxinum'), which is less apparent under unanesthe-

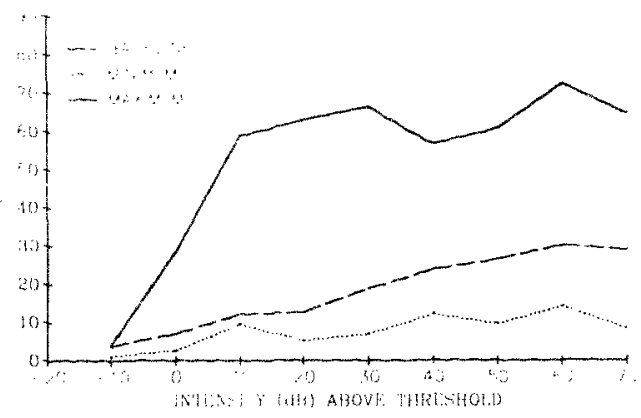

Fig. 4. Amplitude (A-B) input/output functions obtained with different intensities of stimulation at $10 \mathrm{~dB}$ intervals, before (baseline) and following administration of anesthesia. The amplitude value at $-10 \mathrm{~dB}$ reflects the noise revel of the recording system. The value of $0 \mathrm{~dB}$ is the lowest intensity yielding a reliable response. The function labeled 'minimum' was sutained when the response demonstrated a greatest iepressant effect of the anesthesia (approximately $15 \mathrm{~min}$ post-drug). Function labeled 'maxim $m$ ' was obtained during the hyperexcitability period ( $2 \mathrm{~h}$ post-drug). 


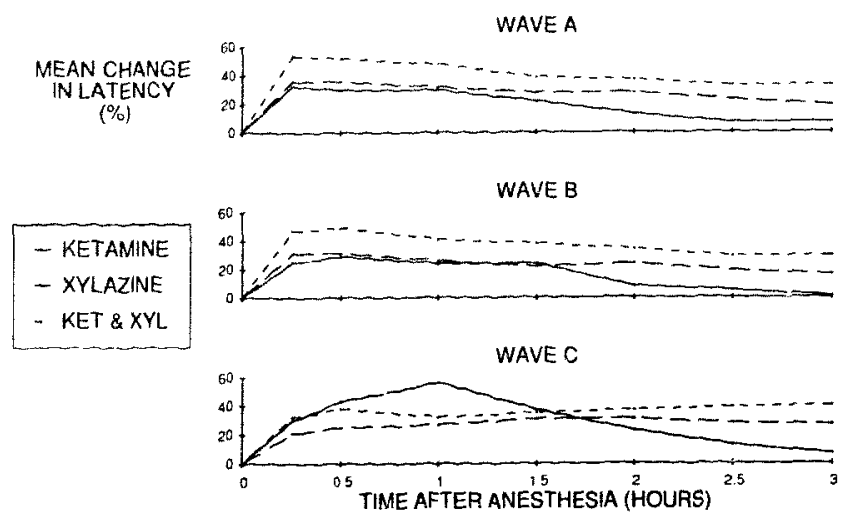

Fig. 5. Changes in latency of wave A, B, and C following administration of ketamine, xylazine, and ketamine plus xylazine. Mean values based upon observations in five subjects.

tized or deep anesthetic conditions. The higher amplitude value shown at threshold $(0 \mathrm{~dB})$ for the function obtained at $2 \mathrm{~h}$ post-anesthesia reflects the greater variability of response observed at this time. While the form of the change in the response function observed in this subject is typical, the magnitude of 'overshoot' measured at $2 \mathrm{~h}$ postanesthetic is greater than the mean 'overshoot' response observed (Fig. 2).

\section{Latency}

All anesthetic regimes caused an increase in the latency of waves A, B, and C (Fig. 5). For all anesthetics the magnitude and duration of the increase in latency was greater for the latter response. The increase in latency of waves $A$ and $B$ were less and of shorter duration, under ketamine alone, and greatest and more prolonged with a combination of ketamine with xylazine. For wave $\mathrm{C}$, the increase in latency was greater with keta-

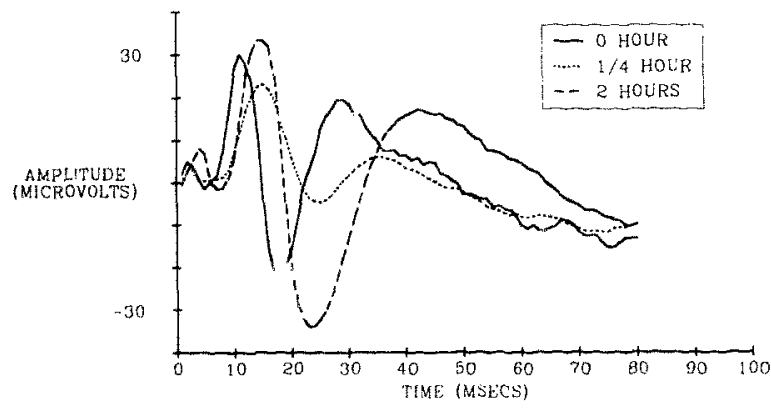

Fig. 6. Waveform morphology of the MLR response observed prior to, one-quarter hour and $2 \mathrm{~h}$ following administration of ketamine with xylazine. mine than xylazine, but the duration of this change was shorter with ketamine. The mean latency of wave $C$ may be artificially low in the ketamine with xylazine group during the first hour after anesthesia. During this period, only two of the five animals exhibited a wave $C$ that could be measured. The sample may be biased toward mure 'resistant' subjects.

\section{Waveform}

As expected from these amplitude and latency changes, the MLR waveform is affected by anesthesia. Later waves are more sensitive to anesthesia, with a tendency to disappear, particularly in the ketamine with xylazine group. Ther was a marked initial suppression of the $B$ and $C$ waves which were either reduced in size or disappeared completely. The $A$ wave was least affected in amplitude but took on a broader appearance. During recovery, the $B$ wave returned prior to the $C$ wave, both gradually increasing in size with time. A representative illustration of these changes in one guinea pig, typical for a mean response change (Figs. 2 and 3), is shown in Fig. 6. In all cases at $24 \mathrm{~h}$ amplitude, latencies and morphology had returned to their pre-anesthetic values.

\section{Discussion}

Current clinical interest in the MLR necessitated a clarification of the possible effects of anesthesia in this response. Recent data (Kileny and Kemink, 1987) indicates that the EMLR may 
be useful in co hlear implant patients when no anesthesia is ustd. In humans, the MLR is mildly delayed. but preserved when a balanced nitrous oxide/narcotic anesthesia technique is used (Kileny et al., 1983; Kileny, Kemink and Miller, 1989).

The three anesthetics studied in this investigation consistently caused significant changes in suprathreshold characteristics of the guinea pig MLR. Importantly, threshold is unaffected. Given our methodology, threshold could be studied reliably to within $+/-5 \mathrm{~dB}$. It may be that with greater precision of threshold determination an anesthetic dependent change in sensitivity would be detected. However, $5 \mathrm{~dB}$ precision is a typical criteria used in MLR as well as other non-invasive evoked potential studies, and thus, we suggest that the anesthetized preparation can be used for investigation of threshold without compromising the validity or sensitivity of this measure.

Following anesthesia, the amplitude of the response is depressed while latencies of waves A, B, and $C$ are prolonged. With time the latencies return gradually towards normal, while the amplitude increases to a value well above the preanesthetic baseline. This increase in amplitude probably follows the course of charge in depth of anesthesia. It coincides with the return of the withdrawal reflex. The magnitude and duration of the amplitude and latency changes differed between the three groups being least with ketamine and greatest with ketamine and xylazine combined, and the differences were consistent with the suppression and return of the withdrawal reflex. Similar latency and amplitude changes have been described by Smith and Kraus (1987) using a variety of anestheties, including barbituates. Thus, the effect is not specific to one type of anesthetic agent and appears to reflect a generalized anesthetic state and depth of anesthesia.

It is interesting to speculate on the prssible causes of the amplitude changes caused by anesthesia. The initial reduction is likely to be due to general CNS depression from the drugs. The latter increase is more difficult to explain. Smith and Kraus (1987) showed that the increase in amplitude was not a result of the increased signal to noise ratio caused by sedation, since curare paralysis did not cause amplitude changes. They postulated a selective depression of inhibitory auditory pathwavs resulting in an increased amplitude of the response. Another possible cause may be that the MLR generator sites recover from anesthetic depression more rapidly than competing generators in surrounding neural tissue which remains relatively electrically silent. Blood pressure (BP) has been shown to alter the amplitude of the MLR in humans (Kileny et al., 1983), and the changes observed here could be secondary, due to an anesthetic induced reduction in effect of BP. Brown et al. (1989) examined the effects of different anesthetics, including ketamine with xylazine, on arterial BP, blood gases, heart rate and respiration in the guinea pig. Ketamine with xylazine was found not to alter cardiovascular parameters, however the dose used in their study was small, approximately one-third of that used here. Brown et al. (1989) postulated that the relatively light level of anesthesia was one reason for the stability of the BP. Whether or not a large dose of the anesthetic would affect BP requires further investigation.

Similar alterations to the MLR, by anesthesia, have been seen when the response was evoked by electrical stimulation of the cochlea or cochlear nucleus (CN) (Crowther et al., 1989). The effect of the anesthetic is not dependent upon the receptor, but on the central auditory pathway.

The differential effect of anesthesia on the three waves of the MLR may suggest different generator sites for each wave. Dafny and Rigor (1978) suggested that ketamine anesthesia may not prevent sensory information from reaching the cortical receiving regions but it may fail to be perceived in some of the association regions because these centers are depressed. In this study, wave A was most resistant to anesthesia. This is consistent with the suggestion that the wave A generator site may be in primary auditory cortex, while the more sensitive waves B and C may originate from association areas.

Although the MLR remains present during anesthesia, suprathreshold response characteristics are affected greatly. This is of importance to all those examining the MLR in clinical practice and in the laboratory. Of particular significance is the major effect anesthesia has on amplitude and thus, the change effected on amplitude growth func- 
tions. Since the changes are relatively predictable, it is possible to study amplitude and latency functions in an anesthetized animal. However, since the effects may change dramatically when using boluses of parenteral anesthetic, a constant infusion may be more appropriate to produce more stable response. If the experimental design or conditions of a study do not allow testing to be conducted in the awake preparation, MLRs should be recorded during a stable period. The results of this study indicate that while anesthesia with such commonly used agents as ketamine and xylazine does affect the general configuration of the MLR, threshold of the response is not affected and it is possible to identify stages where the response is stable.

\section{Acknowledgements}

This work was supported in part by a National Institutes of Health grant No. NS-21440, Food and Drug Administration contract No. 223-876028, and a Fellowship from The TWJ Foundation, Inc.

\section{References}

Brown, J.N., Thorne, P.R. and Nuttall, A.L. (1989) Blood pressure in the awake and anesthetized guinea pig. Lab. Anim. Sci. 39, 142-148.

Burton, M.J., Miller, J.M. and Kileny, P.R. (1988a) Middle latency response; I. Electrical and acoustic excitation. Arch. otolaryngol. Head Neck Surg. 115, 59-62.

Burton, M.J., Miller, I.M. and Kileny, P.R. (1988b) Middle latency responses: Il. Variation between stimulation sites. Arch. Otolaryngol. Head Neck Surg. 115, 458-461.

Crowther, J.A., Cannon, S.C., Miller, J.M. et al. (1989) Anesthesia effects on the electrically evoked middle latency response in the guinea pig. Otolaryngol. Head Neck Surg. $101,51-55$.

Dafny, N. and Rigor, R.M. (1978) Neurophysiological approach as a tool to study effects of drugs on the central nervous system: Dose effect of ketamine. Exp. Neurcl. 59 , 275-295.

Detweiler, D.K., Patterson, D.F., Luginbuhi, H. et al. (1968)
Diseases of the cardiovascular system in canine medicine.In: EJ. Catscott (Ed.), American Veterinary Publications, Inc., Santa Barbara, CA and Wheaton, IL, pp. 589-679.

Gardi, J.N. (1985) Human brain stem and middle latency responses to electrical stimulation: Preliminary observations. In: R. Schindier and M. Merzenich (Eds.), Cochlear Implants Raven Press, New York, pp. 351-364.

Green, C.J., Knight. J., Precious, and Simpkin, S. (1981) Ketamine alone and combined with diazepam or xylazine in laboratory animals: A ten year experience. Lab. Anim. 15, 163-170.

Hart, M.V., Rowles, J.R., Hohimer, A.R. et al. (1984) Hemodynamics in the guinea pig after anesthetization with ketamine/xylazine. Am. J. Vet. Res. 45, 2328-2330.

Ho, K.J., Kileny, P., Paccioretti, D. and McLean, D.R. (1987) Neurologic, audiologic and electrophysiologic sequelae of bilateral temporal lobe lesions. Arch. Neurol. 44, 982-987.

Jyung, R.W., Miller, J.M. and Cannon, S.C. (1989) Evaluation of eighth nerve integrity using the electrically evoked middle latency response. Otolaryngol. Head Neck Surg. (in press).

Kileny, P.R., Dobson, D. and Gelfand, E.T. (1983) Middle latency auditory evoked responses during open heart surgery. Electroenceph. Clin. Neurophysiol. 55, 268-276.

Kileny, P.R. and Shea, S.L. (1986) Middle latency and $40 \mathrm{~Hz}$ auditory evoked responses in normal hearing subjects: Click and $500 \mathrm{~Hz}$ thresholds. J. Speech Hear. Res. 29, 20-28.

Kileny, P.R. and Kemink, J.L. (1987) Electrically evoked middle latency auditory potentials in cochlear implant candidates. Arch. Otolaryngol. Head Neck Surg. 112, 1072-1077.

Kileny, P.R., Kemink, J.L. and Miller, J.M. (1989) An intrasubject comparison of electric and acoustic MLRs. Am. J. Otol. 10:23-27.

Kraus, N., Smith, D.I. and Grossmann, J. (1985) Cortical mapping of the auditory middle latency response in the unanesthetized guinea pig. Electroenceph. Clin. Neurophysiol. 62, 2219-226.

Kraus, N., Smith, D.I. and MicGee, T. (1987) Rate and filter effects on the developing middle latency response. Audiology 26, 257-268.

McGee, T.J., Ozdamar, O. and Kraus, N. (1983) Auditory middle latency responses in the guinea pig. Am. J. Otolaryngol. 4, 116-122.

Ozdamar, O., Kraus, N. and Grossmann, J. (1986) Binaural interaction in the auditory middle latency response of the guinea pig. Electroenceph. Clin. Neurophysiol. 63, 476-483.

Smith, D.I. and Kraus, N. (1987) Effects of chloral hydrate, pentobarbital, ketamine and curare on the auditory middle latency response. Am. J. Otolaryngol. 8, 241-248. 